\title{
Case assignment in double object constructions
}

\section{Elisa Vázquez \\ Universidad de Santiago de Compostela}

\begin{abstract}
This paper analyzes how case assignment takes place in double object constructions in English. It has been claimed in the literature that case could be either structural or inherent. I will provide some evidence showing that this distinction is problematic under certain circumstances. In this sense, I will suggest three different possibilities to unify these two processes of case assignment. In the first place, I will consider unification through PP-movement, which seems to work well if we allow different subcategorizations of the same verb. In the second place, I will focus on unification through Inherent Case, pointing out that it cannot account for some of the data presented in this paper. Finally, I will discuss and give arguments for the unification through Structural case.
\end{abstract}

\section{Introduction}

It was first assumed by Chomsky in his book Lectures on Government and Binding (1981) that when structural (i.e. positional) Case is assigned to an NP, both the government condition and the adjacency condition, summarized in (1) and (2) below, should be respected.

(1) Government Condition: Structural Case is assigned to an NP that is governed by the verb. In very general terms, what is relevant for a better understanding of this paper is that the verb is at the same level as the NP complement in the tree diagram. In other words, the 
verb and its complement are sisters. For a more formal definition of government, cf. Chomsky, Barriers 8 .

(2) Adjacency Condition: Structural Case is assigned to the NP that immediately follows the verb.

In principle, a verb must not only govern its complement but it must also assign a case and a semantic role to it. At the same time, structural case assignment must be further constrained by adjacency in the sense that only the object that comes just after the verb can be assigned structural Case.

Some problems arise, however, as to how structural case is assigned in certain double NP constructions in English. Essentially, it is hard to see how the two conditions given in (1-2) above can be fulfilled in the case of a ditransitive verb such as "give." These problems led Chomsky to search for an additional way of assigning Case, namely, the process of inherent Case assignment (Barriers 193-194). As I will show below, this resulted in the binarization of Case Theory. Consider the following data

(3) a. John gave a present to Mary.

b. John gave Mary a present.

In (3a) "a present" is assigned structural case by "gave," while in (3b) "Mary" is inserted between "gave" and "a present," violating thus the adjacency condition. In these terms, "a present" cannot be assigned structural case but rather inherent case. To solve this contradiction, Chomsky claims that inherent case is closely related to certain theta roles and, therefore, it is assigned according to idiosyncratic properties of verbs (Knowledge of Language 193). As Webelhuth puts it, "inherent Case necessitates a thematic dependence of the NP receiving the Case on its Case assigner, while Structural Case is not subject to such as condition" (56).

Unfortunately, the examples under (3) above prove that this claim raises many problems as well. In fact, we note that the NP "a present" receives the same theta role, namely Theme, from the verb "gave" both in (3a) and (3b), even though in the former it bears structural case while in the latter it bears inherent case. That is, the same NPs which receive the same theta-role by the same verb are under different case assignment processes. In short, it seems that the proposal that only inherent case is closely related to the theta-role cannot be sustained.

In the following sections, I will suggest three apparently plausible solutions to unify these two case assignment processes. First of all, I will analyze the unification through $P P$ movement. Afterwards, I will focus on the unification through Inherent Case. Finally, I will show how the unification through Structural Case could take place. 


\section{Unification in Case Theory}

\subsection{Unification through PP-movement}

Consider this first proposal in sentences such as (3a-b) above. From a semantic point of view, we can assume that there is no difference between them. Their D-structure is (4)

(4) John gave (PP (P O)) a present to Mary.

In (4) I assume that there is an "invisible" PP before the two objects. To be more specific, my preliminary suggestion is that this bracketed PP does not affect (structural) case assignment. Anyhow, since PP movement is optional, there are two possible derivations at S-structure for (4). When "to Mary" moves, (3b) is derived. (I take for granted here that the preposition to does not surface at this level of representation because it is regarded as "null" or "semantically empty." If, on the contrary, "to Mary" remains in situ, (3a) is obtained. When PP-movement occurs, "Mary" does not violate the Case Filter (which basically means that NP arguments must have case) because it is already assigned case by the preposition "to." At the same time, the verb "gave" and the NP "a present" satisfy both the government and the adjacency condition since the PP is an "invisible PP." Thus, the verb "gave" can assign structural accusative case to "a present." The evidence for assuming (4) as the D-structure for (3a) and (3b) is the following:

(5) a, John gave a present.

b. *John gave Mary.

In (5b) "Mary" satisfies the government condition and the adjacency condition in relation to the verb "gave" and it can be assigned a case. The result is, however, ungrammatical. The reason why the preposition "to" is treated as "null" is that it seems to function as a case marker rather than as a "true" preposition with a semantic value. We may wonder about the possibility of having PP-movement under this assumption. Apparently, there should be no problem, since the pure intention of Move-a is to move any category to any place. In Wh-movement, the Wh-phrase must move from the site on which case in assigned to a caseless position. In NP movement, the NP phrase must move from the caseless position to the case assigning position. These two movements can be said to be obligatory. PP-movement, on the other hand, involves movement to a position which is unrelated to a case and, therefore, it is optional. The only problem with this assumption is that we should admit the two possible subcategorizations of "give," namely [+

$\mathrm{NP}(\mathrm{PP})]$ and $[+$ (NP) NP].

\subsection{Unification through Inherent Case}

In this section, I will discuss the unification through inherent Case. Let us begin by having a look at the following pair of sentences. 
(6) a. They believe the doctrine.

b. Jane thanked Tom.

In (6a) the NP "the doctrine" bears accusative case, while "Tom" in (6b) bears dative case. It is obvious that these phenomena have a close relation with theta-role assignment, as I have claimed above. More precisely, the object in (6a), i.e. "the doctrine," bears the thetarole of Goal. According to Wasow, the direct object to which accusative case was assigned can be the subject of the predication with a suffix " able" attached to a verb (333). This explains the contrast we get between (7a) and (7b)

(7) a. The doctrine is believable.

b. *Tom is thankable.

From (7) we conclude that the object of "believe" has accusative case and the object of "thank" has dative case. This conclusion will be further supported below. Consider now (8)

(8) Jane's thanks to (*of) Tom went unknowledged.

We cannot explain the difference between these two sentences above by referring to Chomsky's structural case assignment. We know that structural case is assigned only if the government and adjacency conditions are satisfied, without taking into account the contents of the lexical entry. On the other side, inherent case has a lot to do with the choice of a lexical entry. This is illustrated in (9-11) below:

(9) a. They taught handicapped children manual skills.

b. They taught handicapped children.

(10) a. Their teaching of manual skills to (*of) handicapped children was admirable.

b. Their teaching of $(*$ to $)$ handicapped children was admirable.

(11) a. Manual skills were teachable to handicapped children.

b. *Handicapped children were teachable of manual skills.

c. Handicapped children were teachable.

In the sentences above, the same NPs, "handicapped children," which are used as an object of the same verb, "teach," are assigned dative case when they receive the theta role Goal, and while accusative case is assigned when they receive the theta-role Theme. We find the same pieces of evidence both in (10) and (11). Once again, we cannot account for this phenomena with our structural case unification proposal.

I have argued that these features are recorded in the Lexicon, and, therefore, inherent case assigment and theta-role are dependent on each other. This can also be observed in French.

(12) a. Pierre vous cherche. 
"Pierre is looking for you."

b. Pierre vous parle.

"Pierre is speaking with you."

(13) a. Pierre le cherche.

b. Pierre lui parle.

In (12a) "vous" functions as direct object and receives structural accusative case, so that it can be substituted by a third person direct object clitic, "le," in (13a). In turn, "vous" in (12b) receives dative case a an indirect object and, therefore, it can be substituted by a third person indirect object clitic, "lui," in (13b). In these sentences "vous" and "lui" can be assumed to have a function not so much of an object as of a "pro-form" which represents a prepositional phrase, an NP.

As we have seen above, if a verb assigns structural case only in terms of the configuration in French as it does in English, we cannot explain the difference in theta roles of the two cases because in (12a) and (12b) "vous" has the same form. In this sense, my proposal is to let a verb assign inherent case to its object and, in addition, to let the verb assign only the case "written" in the Lexicon to an NP it governs. The Case Filter will play the important role of checking whether the inherent case "written" in the Lexicon is assigned properly or not.

Consider the following sentences:

(14) a. John gave Mary a present

b. [IP John [I' [VP gave Mary [NP a present]]

In the syntactic representation given in (14b), we note that the verb "give" governs both the NP "Mary" and the NP "a present." The proper subcategorization of "give" would be spelled out as follows:

$$
\begin{aligned}
\text { (15) give: } & +[\text { [ } \\
& + \text { Goal }+ \text { Theme } \\
& + \text { Dative }+ \text { Accusative }
\end{aligned}
$$

On the basis of the features above, the verb "give" assigns dative case to "Mary" and accusative case to "a present." If the case assignment took place in the opposite direction, namely if "Mary" received accusative case and "a present" dative case, the Case Filter would rule them out as ungrammatical.

So far we have considered the unification of the binarized Case Theory under the assumption that the whole information of a verb, such as its subcategorization, theta roles that it takes, and the case to be assigned in a sentence is shown in the lexical entry. As we will see in the following sentences, there are also some problems with this approach.

(16) a. * John gave Mary secretly a present.

b. * John sent Robert suddenly a telegram.

c. * Who did John give a book? 
It is clear that the ungrammaticality of $(16 a-b)$ follows from that a violation of the adjacency condition. As for (16c), we note that Move- $\alpha$ cannot be applied to an indirect object. It seems, then, that even if we modify the twofold Case Theory into the one proposed in this section, we will not be able to account for data like (16).

\subsection{Unification through Structural Case}

Our second point for discussion refers to the possibility of getting rid of the notion of inherent case and assuming that every instance where case is assigned to a phrase/word it is assigned structurally.

Let us begin by analyzing our reason for this suggestion. Consider the following sentences:

(17) a. [IP John [VP [V gave Mary] [NP a present]]]

b. [IP Tom [VP [V sent Robert] [NP a telegram]]]

c. [IP Jane [VP [V threw Bill] [NP the ball]]]

When we try to unify the two processes of Case assignment in the double NP construction, the generally accepted conditions of adjacency and government need to be respected. This third possibility of unifications is based on the assumption that we can reconstruct the structure in question into the structure (v V--NP), which is one of the word-formation rules. In (17) we make up a complex verb by combining a verb and its first adjacent object and then this complex verb assigns case to the second object. In fact, we assume this second object to be the object of the complex verb. This configuration satisfies the conditions of government and adjacency. There is, however, a further problem arises here with respect to the question of how the NP which is the first object of a verb can hold its case. Consider the following tree:

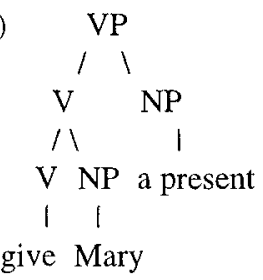

In this structure above, two different ways of assigning case are potentially possible. One option would be to argue that the NP "Mary" receives case and holds it because the verb "give" and the NP "Mary" satisfy government and adjacency. The second one would be to claim that the case of the NP "Mary" is absorbed because the NP "Mary" is combined with the verb "give" to form a complex verb. In this case, even though absorption takes place, the NP "Mary" can still be expected to have the imaginary case-trace in the upper 
level, the Case Filter being thus respected. Yet, in (17a-b) the NP "Mary" has the theta role Goal. When we think of the result of the predicate, we can assume that the NP "Mary" has an additional theta role Possessor which possesses the second NP "a present." Obviously, this does not mean that an NP can have two theta roles. On the contrary, we cannot assume such kind of relation in (18), so restructuring is ruled out. The relation we get is shown in (19) and (20) below:
a. Mary has a present.
b. Robert has a telegram.
c. Bill has the ball.
a. * Canada has a telegram.
b. * The ground has the ball.

In other words, to make a complex verb, the first NP must have a theta role either of Possessor or Recipient of the second NP. Look at the following examples:
a. This problem is giving John a headache.
b. This book has given me an idea.
c. You should not begrudge John his wealth.

In (21a-c), the first NP is combined with a verb to form a complex verb. As we can see, all the first objects have an additional theta role Possessor and they possess their second objects. This is a very peculiar property. Along these lines, it is reasonable to argue that the NP bearing the theta role Possessor forms, first, a complex verb with the verb and then this complex verb assigns structural case to the second object. To prove this suggestion, let us consider the following sentences derived by application of Wh-movement:
a. What did Tom send Robert
b. Which record did Tom give Mary
c. What did Mary bake her mother
d. What did you begrudge John
a. * Who did John send a telegram?
b. * Which girl did Tom give a record?
c. * Whose mother did Mary bake a birthday cake?
d. * Who don't you begrudge his wealth?

In (22) it is possible for a verb and its first following object to be combined to form a complex verb. As we have suggested, it is this complex verb that assigns case to the adjacent (second) object. The empty space " " stands for the Wh-trace and, as such, it gives its case to the Wh-phrase which was moved to the beginning of each of these sentences, yielding the sentences under (22) grammatical. In contrast, the set of examples under (23) is explained on the following grounds: in each of these four sentences, the first object is incorporated into the preceding verb to form a complex verb and, therefore, this 
object is considered a constituent of a proper verb. Consequently, Move- $\alpha$ cannot apply to a part of a constituent, the complex verb in this case. This is shown in (24) below:

a. [CP COMP [IP John [VP [V' [V give Mary] a book]]]]

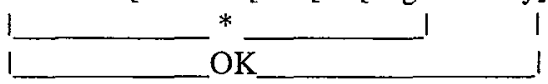

b. *Mary John gave a book.

c. A book John gave Mary.

From the sentences presented so far, we can conclude that in double NP constructions in English, Wh-movement can never be applied to the first object which is combined with a preceding verb to form a complex verb. Needless to say, in this process we should accept the premise that Wh-movement is applied after the restructuring and case-marking.

Take into account now the following sentences with NP movement:
a. *John is the guy that Robert sent a telegram.
b. * I met a girl that Tom gave a record.
c. * Robert wasn't easy to send a telegram.
d. * Anne is hard to give anything.
e. * It was Robert that Tom sent a telegram.
f. * Was it Anne that John gave the record?

(25a-f) are all ungrammatical because NP-movement is applied to the first NP in the complex verb. In the case of (25a-b), ungrammaticality is obtained since the NPs in the complex verbs such as "sent the guy" and "gave a girl" are separated from the verbs by NP-movement. (25c-d) show that movement of an NP out of a complex verb such as "be easy to," or "be hard to" is not allowed. Finally, the cleft constructions under (25e-f) are also out since they are derived by extraction of an NP from a complex verb. In sum, it seems clear that our preliminary hypothesis of unification through inherent case cannot account for all the data discussed under (25).

Next, I will look over the passivized double NP construction, which is derived by the NP-movement. Consider (26)
a. Robert was sent a telegram.
b. Anne was given a record.

If these two sentences were in the active voice and the first objects of the active sentences were part of a complex verb, NP-movement of these first objects could not take place. The reason why (26a-b) are grammatical is that we do not regard them as derived from their double NP construction counterparts, which are given in (27) below:
a. They sent a telegram to Robert.
b. They gave a record to Anne. 
In (27) the preposition "to" is probably thought of as a dummy case marker. In other words, the preposition is functioning as a case assigner which appears to help NPs such as "Robert" and "Anne" to escape the Case Filter when they are not moved. This is similar to the case of French "a," that enables us to apply Move-a to the indirect object after the dummy case marker. Therefore, it is reasonable to claim that the sentences in (25) are derived from those in (26). What happens, though, if we have some other preposition? Just as a digression, let us compare the preposition "to" with "in" and "on" in the following sentence:

c. John gave a book to Mary in the library on Sunday.

Does "to" have a stronger property as a preposition or as a case marker in this sentence? Without any doubt, it can be claimed that "to" is functioning as a case marker, whereas "in" and "on" bear some semantic content. Thus, I argue that it is more accurate to give "to Mary" a structure like (27d) below, while other PPs such as "on Sunday" and "in the library" should be analyzed under (27e). Furthermore, these two different PPs are inserted into higher VPs with different structures. More precisely, the PP in the structure under (27e) is a complement PP immediately dominated by the VP node, whereas the PP in (27d) is an adjunct immediately dominated by the IP-node.
(27) d. PP
$\wedge$
P NP
(27) e. PP
$\Lambda$
Spec Head
Case marker
P NP
Head Complement
Preposition

Consider now the following data:
a. * A telegram was sent Robert.
b. * A record was given Anne.

In (28) above, if we assume that "a telegram" is a real object of a complex verb in the active mood, Move-a is allowed and the sentences should be grammatical. Since this is not the case, we may argue that Move-a takes place in (27) but not in (28) Moreover, it is also worth mentioning that the passive-participle and the following indirect object are not combined to form a complex verb.

In fact, there is little difference on the grammaticality judgements given by scholars regarding the passivized double NP construction. These judgements are shown in the table below:
A $\quad$ B $\quad$ C

$\begin{array}{lllll}\text { a. The book was given to Mary. } & \text { ok } & \text { ok } & \text { ok } & \text { ok } \\ \text { b. Mary was given the book. } & \text { ok } & \text { ok } & \text { ok } & \text { ok } \\ \text { c. The book was given Mary. } & \text { ok } & \text { ok } & \text { ok } & *\end{array}$



a. The book was bought for Mary.
b. Mary was bought the book.
ok ok ok ok
c. The book was bought Mary.
* ? ok ok
* * ok *

A corresponds to Fillmore (The case for case $1 \mathrm{ff}$.), $B$ to Jackendoff and Culicover (397ff.), $C$ to Allerton (22ff.), and, finally, I give my own non-native intuitions in $D$.

According to Fillmore (33), sentences such as those given in (31) below have a Dstructure like (32)

(31) a. John gave a book to Mary.

b. John gave Mary a book.

(32) PAST give [Obj a book][to Mary] [by John]

We note that all the NPs in (32) have prepositions as obligatory constituents in the representation. If NP is under the process of subjectivalization or objectivalization, it loses its preposition. In particular, the NP with the feature of objectivalization can be a subject of a passive sentence. This explains the grammaticality of the sentences in (33)
a. A book was given to Mary by John.
b. Mary was given a book by John.

On the other hand, Givon regards NP1 in the double object construction as a piece of "old information" and names it Topic. At the same time, he regards NP2 as a piece of "new information" and names it Focus (160). In this sense, he maintains that in a passive sentence only the NP1 Topic can be moved to the subject position, whereas in a Whquestion sentence, only the NP2 can be moved to the COMP position. Consider the following representations

(34) a. [NP e ] is given Mary a book

I TOPIC FOCUS

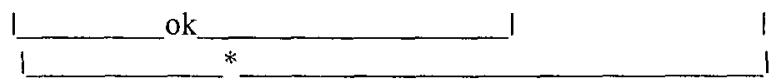

b. [CP COMP does [IP John give Mary a book ]]]

I TOPIC FOCUS

L___

(35) a. When he found it, John gave the book to Mary.

b. * When he found it, John gave Mary the book.

c. When he found her, John gave Mary the book.

d. * When he found her, John gave the book to Mary. 
(36) a. To whom did John give the book ?

i. He gave the book to Mary.

ii. * He gave Mary the book.

b. What did John give to Mary?

i. He gave Mary the book.

ii. * He gave the book to Mary.

When we analyze the above sentences in terms of ordinary word-order, we see that his theory works well. In the four examples under (35) we note that the direct object of the subordinated clause anticipates what the first object -which is also the Topic- of "gave" should be. At the same time, we can conclude from (36) that in response to questions the Topic must occur in the second object position.

At first sight, it seems easy to distinguish a Topic from a Focus but it is also possible to find examples where it is hard to separate one from the other. This is illustrated in (37) below:
a. John gave a book to a man.
b. John gave a man a book.

The fact that both "a man" and "a book" can be regarded as Focus depending on the context, brings out some confusion when (NP or Wh-) movement takes place.

Johnson assumes the hierarchy between subject, direct object, indirect object and oblique case object according to their grammatical function (156ff.). The hierarchy goes as follows:

(38) subject $>$ direct object $>$ indirect object $>$ oblique object

Moreover, he claims that (37a) corresponds to the D-structure of (37b), which is formed by applying the Advancement Rule (i.e. to move an element to an upper position) to (37a). The direct object is, therefore, an NP located just after the verb. In this respect, we should take into account that the indirect object can become a direct object, while the direct object can never turn into an indirect object. Consequently, it remains a Chomeur (Johnson \& Postal 295-310).

(39) JohngaveMarya book $($ Subj)(DO)(DO-Chomeur)

In this example, "a book" becomes a Chomeur because the rule of Advancement was applied to "Mary." The direct object just after a verb of an active sentence is raised to be a subject in a passive sentence. That is how the sentences in (40a-b) are derived.

While many scholars have tried to unify (37a) and (37b) in various ways, Chomsky $(L G B)$ argues for two different D-structures of the passive sentence in (37) above. These are given in (40): 
(40) a. [NP e] was given a book to Mary.

b. [NP e] was given Mary a book.

However, even though there are some advantages in this assumption, the redundancy that results from it cannot be avoided. In addition, it cannot account for sentences such as (41)

$(41) *$ Who did John give a book?

That is, (41) should be grammatical since the Empty Category Principle (ECP), which states that all traces must be properly governed, is not violated. Clearly, Chomsky would need to find a different condition to account for this example. In our approach, though, this problem is successfully solved by restructuring.

\section{Conclusion}

In this paper, I have suggested three different possibilities for the unification of Case Theory, in which two processes of case assignment are assumed. I have analyzed some data that lead us to conclude that neither unification through PP-movement nor unification through inherent case provides a good account of the problems outlined in section 1 (cf. data like (9-11) and (15) above). It is only my third suggestion that gives us a clear idea of what is and what is not grammatical, always with the help of some kind of movement (either Wh-movement or NP movement).

\section{Works cited}

Allerton, D.J. "Generating indirect objects in English." Journal of Linguistics 14 (1978): 21-34. Chomsky, Noam. Lectures on government and binding: The Pisa Lectures, Dordrecht: Foris, 1981. . Barriers. Cambridge, Mass.: MIT Press, 1986 .

Knowledge of Language: Its Nature, Origin, and Use. New York: Praeger, $1986 \mathrm{~b}$.

Culicover, Peter W., and Wendy Wilkins. "Control, PRO, and the Projection Principle." Language 62 (1986): 120-153.

Fillmore, Charles J. Indirect Object Construction in English and the Ordering Transformations. Monographs in Linguistic Analysis 1, Mouton, The Hague, 1965.

."The case for case." Universals in Linguistic Theory. Eds. E.Bach and R.T.Harms.

New York: Holt, Rinehart and Winston, 1968. 1-88.

Givón, Talmy. English Grammar. Amsterdam: John Benjamins, 1993.

Jackendoff, R.S., and P.W. Culicover. "A reconsideration of dative movement." Foundations of Language 7 (1971), 397-412.

Johnson, Kyle. "Object positions." Natural Language and Linguistic Theory 9 (1991): 577-636. Johnson, David E., and P.M.Postal. Arc Pair Grammar. Princeton, New Jersey: Princeton University Press.

Postal, P.M. On raising. MIT Press, Cambridge, Mass., 1974.

Wasow, Thomas. Anaphora in generative grammar. Ghent: Story-Scientia, 1979.

Webelhuth, Gert., ed. Government and Binding Theory and the Minimalist Program. Blackwell, Cambridge, U.S.A, 1995. 